Accelerator Development Department

Associated Universities, Inc.

Upton, New York 11973

RHIC Technical Note No. 33

\title{
THE ROLE OF AN INTERMEDIATE LINAC IN MATCHING \\ THE $H=1$ TO $H=3$ HEAVY ION INJECTION CYCLE OF THE BOOSTER
}

\author{
M.J. Rhoades-Brown
}

January 7, 1988 
The Role of an Intermediate Linac in Matching the $h=1$ to $h=3$ Heavy Ion Injection Cycle of the Booster

M.J. Rhoades-Brown

January 7, 1988 


\section{Section I - Introduction}

The design specifications of $\mathrm{RHIC}^{1}$ call for an $\mathrm{h}=1$ acceleration cycle in the Booster, where $h$ is the harmonic number of the Booster radio frequency. However, because of technical considerations, the initial operation of the Booster will be in the $h=3$ mode. It is strongly expected that the $h=1$ mode will be developed and added at a later date. As an alternative scheme however, we discuss in this note the possibility of simulating the $h=1$ mode in the Booster by injecting at a higher velocity using an external Linac. In this way, it should be possible to achieve injection frequencies associated with the existing $h=3$ cavities. The question is, How big does this Linac have to be?

In an earlier report, ${ }^{2}$ the role of a Linac pre-injector on Booster space-charge limits and heavy ion particle intensities was studied. All of the results presented in reference 2 assumed the $h=1$ mode for the Booster. In this report, after we determine the required size of the Linac, we will relate our result to expected particle intensities by expanding on some of the results from reference 2 .

Section II - Matching $h=1$ and $h=3$

In Figure 1 the three injection arrangements considered here are shown. Arrangements $A$ and $B$ are in reference 2, and arrangement $E$ is added for the analysis here. Arrangement $A$ is currently considered by RHIC injection scheme.

The synchronous angular velocity $\omega_{s}$ of the injected heavy ion is given by $\omega_{\mathrm{s}}=\mathrm{V} / \mathrm{R}$ where $\mathrm{V}$ is the injection velocity and $\mathrm{R}$ the Booster radius. Hence we have;

$$
\beta=\frac{\omega_{H F}^{R}}{h c} \quad \text { where } \quad \omega_{S}=\frac{\omega_{H F}}{h}
$$

and $\omega_{H F}$ is the angular frequency of the rf.

The energy of a heavy ion, after acceleration from Tandem and Linac is

$$
\mathrm{m}_{0} c^{2} \gamma_{\mathrm{L}} \mathrm{A}=\mathrm{m}_{\mathrm{o}} \mathrm{c}^{2} \gamma_{\mathrm{T}} \mathrm{A}+\mathrm{QV}_{\mathrm{L}} \mathrm{e}
$$

where $V_{L}$ is the Linac voltage accelerating charge $Q$ and the notation is explained in reference 2. Hence, in the non-relativistic limit we have on combining (1) and (2);

$$
f_{H F}=\frac{h c}{2 \pi R}\left(\beta_{T}^{2}+\frac{2 \mathrm{QeV}_{L}}{m_{0} c^{2} \mathrm{~A}}\right)^{1 / 2}
$$


where $f_{B F}$. is the rf injection frequency. Equating the expression (3) when $V_{I}=0$ and arbitrary $h$ with $h=1$, we determine the following matching condition for $V_{L}$ i.e. ,

$$
V_{L}=\frac{\left(\mathrm{h}^{2}-1\right) \beta_{\mathrm{T}}^{2} \mathrm{~m}_{\mathrm{o}} \mathrm{c}^{2} \mathrm{~A}}{2 \mathrm{Qe}}
$$

Equation (4) determines how big our Linac should be in MV. For the Booster, we are interested in putting $h=3$. Obviously, from figure 1 , arrangement $E$ is more advantages than $B$, for $Q$ is larger on entering the Linac.

In Figures 2 and 3 the rf frequency (equation 3 ) is plotted as a function of $V_{L}$ for $h=1$. The threshold value of $V_{L}$ is determined from equation (4) on putting $h=3$. Results for both arrangement $B$ and $E$ are shown for $a$ variety of heavy ion species. The values for $\beta_{\mathrm{T}}$ and $\mathrm{Q}$ were taken from reference (1) or (2). As: seen from these figures, stripping foil characteristics dictate that arrangement $E$ is increasingly more efficient over arrangement $B$, as the mass number increaseis. For ${ }^{197}$ Au this difference is a factor of 2.54. Unfortunately, even for ${ }^{197} \mathrm{Au}$, arrangement $\mathrm{E}$ still requires a minimum Linac energy of $50.78 \mathrm{MV}$. This is a substantial machine when measured by any standard.

\section{Section III - Particle Intensities}

We now work out the space-charge limit in the Booster, and the number of ${ }^{197} \mathrm{Au}$ ions/bunch in the Booster using arrangement $\mathrm{E}$ of figure 1 . Arrangement B will be ignored at this point. For ${ }^{997} \mathrm{Au}$ we take the minimum Linac injection energy to be $50.78 \mathrm{MV}$. For the intensity question, the results are compared with the standard injection system (arrangement $A$ of reference 2), where no Linac is present. Both $h=1$ and $h=3$ in the Booster (arrangement $A$ ) will be studied in this comparison, and the results of reference 2 will be used in part.

Using the notation of reference 2, the space-charge limit in the booster for the standard injection system (arrangement A) is,

$$
\mathrm{N}_{\mathrm{A}}^{\mathrm{SC}}=8.8 \times 10^{10} \delta \nu \mathrm{V}_{\mathrm{T}}\left(\frac{\mathrm{Q}_{\mathrm{T}}+1}{\mathrm{Q}^{2}}\right)
$$

For arrangement $\mathrm{E}$ of figure 1, this formula is modified to read,

$$
\mathrm{N}_{\mathrm{E}}^{\mathrm{SC}}=\mathrm{N}_{\mathrm{A}}^{\mathrm{SC}}\left(1+\frac{\mathrm{V}_{\mathrm{L}} \mathrm{Q}}{\mathrm{V}_{\mathrm{T}}\left(\mathrm{Q}_{\mathrm{T}}+1\right)}\right)
$$


Table 1. Space-Charge Limits of Booster for Arrangements $A$ and $E$. ${ }^{197} \mathrm{Au}, \mathrm{Q}_{\mathrm{T}}=13, \mathrm{Q}=33, \mathrm{~V}_{\mathrm{T}}=15 \mathrm{MV}, \mathrm{V}_{\mathrm{L}}=50.78 \mathrm{MV}$.

\begin{tabular}{c|c|c}
\hline \multirow{2}{*}{$\delta \nu$} & $\mathrm{N}_{\mathrm{A}}$ & $\mathrm{N}_{\mathrm{E}}^{\mathrm{SC}}$ \\
\hline .1 & $.170 \times 10^{10}$ & $1.526 \times 10^{10}$ \\
.3 & $.509 \times 10^{10}$ & $4.571 \times 10^{10}$ \\
.5 & $.848 \times 10^{10}$ & $7.615 \times 10^{10}$ \\
\hline
\end{tabular}

Obviously, for ${ }^{197} \mathrm{Au}$ we find $\mathrm{N}_{\mathrm{E}}^{\mathrm{SC}}=9.0 \times \mathrm{N}_{\mathrm{A}}^{\mathrm{SC}}$.

In order to estimate the particle number/bunch in the Booster, it is necessary to consider the efficiency of the initial multi-turn injection. In the discussions of reference 2, we assumed 100\% stacking efficiency for an eight turn injection and $50 \%$ stacking efficiency for a 32 turn injection. ${ }^{3}$ These assumptions appear compatible with the recent numerical simulations of Wei and Lee who achieved $80 \%$ stacking efficiency in a 20 turn injection. For the discussion in this paper we assume the stacking efficiency of reference 2.

The number of revolutions $N$, possible for a given pulse length $\mathrm{P}^{\mathrm{L}}$ from the Tandem is;

$$
N=\frac{\beta_{T} c P^{L}}{2 \pi R}\left(I+\frac{V_{L} Q}{V_{T}\left(Q_{T+1}\right)}\right)^{1 / 2}
$$

Table 2. Number of Revolutions in Booster for $V_{L}=50.78 \mathrm{MV}$. ${ }^{197} \mathrm{Au}$

\begin{tabular}{r|r}
\hline \multicolumn{1}{c|}{$\mathrm{P}^{L}$} & $\mathrm{~N}$ \\
\hline $40 \mu \mathrm{S}$ & 8 \\
$80 \mu \mathrm{s}$ & 16 \\
$110 \mu \mathrm{s}$ & 22 \\
$200 \mu \mathrm{s}$ & 41 \\
$500 \mu \mathrm{s}$ & 103 \\
\hline
\end{tabular}

Let us finally work out and compare the number of injected ${ }^{197} \mathrm{Au}$ ions/bunch in the Booster using a $50.78 \mathrm{MV}$ intermediate Linac, shown in Figure 1 as arrangement $E$. We also tabulate the number of ions/bunch using the standard or accepted injection system ${ }^{1}$ i.e. arrangement $A$ of reference 2 . For this arrangement we show results for $h=1$ and $h=3$, where for the latter we simply divide the results for $h=1$ by a factor of 3 . The particle intensities worked out in Table 3 below assumed the stripping foil efficiencies and device transmission factors in the RHIC manual. ${ }^{1-2}$ For the Linac we assume a transmission factor of .5. Even if these numbers change slightly in the near future, the general qualitative conclusions presented here will not change. 
Table 3. Number of ${ }^{197} \mathrm{Au}$ ions/bunch in the Booster, as function of Tandem Source Current $\mathrm{I}^{\mathrm{S}}$ and Pulse Length $\mathrm{P}^{\mathrm{I}}$.

\begin{tabular}{|c|c|c|c|c|c|c|c|}
\hline$I_{S}$ & $P_{I}$ & $\begin{array}{c}\text { \# Injected } \\
\text { in } 8 \text { turns } \\
h=1\end{array}$ & $\begin{array}{c}\# \text { Injected } \\
\text { in } 32 \text { turns* } \\
h=1\end{array}$ & $\begin{array}{c}\# \text { Injected } \\
\text { in } 8 \text { turns } \\
h=3\end{array}$ & $\begin{array}{c}\text { \# Injected } \\
\text { in } 32 \text { turns* } \\
h=3\end{array}$ & $\begin{array}{l}\text { \# Inject } \\
\text { in } 8 \text { tur } \\
\text { with Lin }\end{array}$ & $\begin{array}{c}\text { \# Injec } \\
\text { in } 32 t \\
\text { with }\end{array}$ \\
\hline $80 \mu \mathrm{A}$ & $40 \mu \mathrm{s}$ & $.048 \times 10^{10}$ & $\cdots \times 10^{10}$ & $.016 \times 10^{10}$ & $\cdots \times 10^{10}$ & $.024 \times 10^{10}$ & $\cdots \times 10^{1}$ \\
\hline $80 \mu \mathrm{A}$ & $80 \mu \mathrm{s}$ & $.096 \times 10^{10}$ & $\ldots \times 10^{10}$ & $.032 \times 10^{10}$ & $\ldots \times 10^{10}$ & $\times 10^{10}$ & $10^{10}$ \\
\hline $80 \mu \mathrm{A}$ & $110 \mu \mathrm{s}$ & $.132 \times 10^{10}$ & $\ldots \times 10^{10}$ & $\times 10^{10}$ & $\ldots \times 10^{10}$ & $\times 10^{10}$ & $10^{10}$ \\
\hline $80 \mu \mathrm{A}$ & $200 \mu \mathrm{s}$ & $.138 \times 10^{10}$ & $\cdots \times 10^{10}$ & $\times 10^{10}$ & $\cdots \times 10^{10}$ & $\times 10^{10}$ & $\times 10^{10}$ \\
\hline $80 \mu \mathrm{A}$ & $500 \mathrm{\mu s}$ & $: 138 \times 10^{10}$ & $276 \times 10^{10}$ & $\times 10^{10}$ & $092 \times 10^{10}$ & $\times 10^{10}$ & $.0469 \times 10^{10}$ \\
\hline $10 \mu \mathrm{A}$ & $40 \mu \mathrm{s}$ & $.066 \times 10^{10}$ & $\cdots \times 10^{10}$ & $\times 10^{10}$ & $\ldots \times 10^{10}$ & $\times 10^{10}$ & $\cdots \times 10^{10}$ \\
\hline $10 \mu \mathrm{A}$ & $80 \mu \mathrm{s}$ & $.132 \times 10^{10}$ & $\ldots \times 10^{10}$ & $\times 10^{10}$ & $\times 10^{10}$ & $\times 10^{10}$ & $\times 10^{1}$ \\
\hline $110 \mu \mathrm{A}$ & $110 \mu \mathrm{s}$ & $.182 \times 10^{10}$ & $\ldots x 10^{10}$ & $.0607 \times 10^{10}$ & $\ldots \times 10^{10}$ & $\times 10$ & $\times 10^{1}$ \\
\hline $110 \mu \mathrm{A}$ & $200 \mu \mathrm{s}$ & $.190 \times 10^{10}$ & $\ldots \times 10^{10}$ & $.0633 \times 10^{10}$ & $\ldots \times 10^{10}$ & $\times 10^{10}$ & $.0649 \times 10^{1}$ \\
\hline $110 \mu \mathrm{A}$ & $500 \mu \mathrm{s}$ & $.189 \times 10^{10}$ & $379 \times 10^{10}$ & $.0633 \times 10^{1}$ & $126 \times 10^{10}$ & $\times 10^{1}$ & $.0644 \times 10^{3}$ \\
\hline $200 \mu \mathrm{A}$ & $40 \mu \mathrm{s}$ & $.122 \times 10^{10}$ & $\cdots \times 10^{10}$ & $.0407 \times 10^{1}$ & $10^{10}$ & $\times 10^{10}$ & $\ldots \times 10$ \\
\hline $200 \mu \mathrm{A}$ & $80 \mu \mathrm{s}$ & $.243 \times 10^{1}$ & $\cdots \times 10^{10}$ & $.0810 \times 10$ & $\cdots \times 10^{10}$ & .061 & $\times 10$ \\
\hline $200 \mu \mathrm{A}$ & $110 \mu \mathrm{s}$ & $.333 \times 10^{10}$ & $\ldots \times 10$ & $\times 10$ & $\ldots \times 10^{10}$ & $.0605 \times 10^{10}$ & $\times 10^{10}$ \\
\hline $200 \mu \mathrm{A}$ & $200 \mu \mathrm{s}$ & $.335 \times 10$ & $\ldots \times 10$ & .111 & $\times 10^{10}$ & $.0571 \times 10^{10}$ & $\times 10^{10}$ \\
\hline 200 & 500 & $.345 \times 10^{10}$ & $690 \times 10$ & $\times 10^{10}$ & 23 & $.0586 \times 1$ & $x 10^{1}$ \\
\hline 300 & $110 \mu \mathrm{s}$ & $.499 \times 10^{10}$ & $\cdots \times 10^{1}$ & $.166 \times 10$ & $\ldots \times 10$ & $.0907 \times 10$ & $\times 10$ \\
\hline
\end{tabular}

$* 50 \%$ Stacking Efficiency.

Table 3 clearly shows the importance of considering the multi-turn injection scheme in the Booster, when deciding on the usefulness of an intermediate Linac. For an eight turn injection, the sizable Linac required to match $h=1$ with $h=3$ dictates that a $40 \mu \mathrm{s}$ pulse from the Tandem is sufficient for saturation. It is very important to note that for arrangement A, i.e. no intermediate Linac and $h=1$ in the Booster, that the number of particles/bunch is greater than a factor of 2 over injection following the $50.78 \mathrm{MV}$ Linac. The factor of 2 is for a $40 \mu \mathrm{s}$ pulse; for a pulse of length $200 \mu \mathrm{s}$ this factor is seen to be approximately 5.8. Even for $\mathrm{h}=3$ and no intermediate Linac the number of ions/bunch is larger than arrangement $E$ if the pulse length is longer than $60 \mu \mathrm{s}$. If we increase the transmission factor through the Linac to .8 , the same argument holds for $h=1$ and no Linac, and a $90 \mu \mathrm{s}$ pulse for $\mathrm{h}=3$ and no linac. As far as particle intensities are concerned, the presently available ion sources make the intermediate linac a poor proposition, even when compared to $h=3$ in the Booster with no Linac.

Turning the argument around, in order to reach the required intensity ${ }^{1},{ }^{2}$ of $2.2 \times 10^{9}$ ions/bunch with a $50.78 \mathrm{MV}$ intermediate Linac for ${ }^{97} \mathrm{Au}$, we require an ion source of $7.33 \mathrm{~mA}$ for a $110 \mu \mathrm{s}$ pulse and an eight turn injection. For a $50 \%$ efficient 32 turn injection a $3.86 \mathrm{~mA}$ is required for a $200 \mu \mathrm{s}$ pulse. Obviously, these sources are not available at the present time, but these numbers are useful for near future discussions of ion sources and intermediate Linac requirements. 
Section IV - Conclusions and Suggestions for the Future

1) It is indeed possible to match $h=1$ and $h=3$ modes in the Booster using an intermediate Linac, however the machine required is quite substantial. For ${ }^{12} \mathrm{C}$ we require a $118 \mathrm{MV}$ Linac and for ${ }^{197} \mathrm{Au}$ a $50.78 \mathrm{MV}$ Linac. This corresponds to $59 \mathrm{MeV} / \mathrm{A}$ for ${ }^{12} \mathrm{C}$ and $8.51 \mathrm{MeV} / \mathrm{A}$ for ${ }^{19} \mathrm{Au}$. These numbers correspond to arrangement $\mathrm{E}$ in figure 1, i.e. the stripping foil before the Linac. For arrangement B, i.e. the stripping foil after the Linac, the required linac voltage is scaled upwards as in figures 2 and 3.

2) The vastly different Linac specifications, for different heavy ion species, will present a design problem in itself. Not only is the linac required quite substantial but the energy verses mass requirements go beyond existing Linac specifications. For instance the Stony Brook system can accelerate ${ }^{12} \mathrm{C}$ to $10 \mathrm{MeV} / \mathrm{A}$ but for ${ }^{197} \mathrm{Au}$ only $2.5 \mathrm{MeV} / \mathrm{A}$ is possible. We note that the Stony Brook system is considered a major low energy heavy ion facility that took several years to achieve its present status.

3) The stacking efficiency in the booster dictates that the number of particles/bunch will decrease significantly in the booster if an intermediate linac is utilized. In fact, even the $h=3$ mode and no Linac is preferable on this count, with the present heavy ion sources.

In view of the above discussions and the results of reference 1 , it strongly appears that unless significant advances in heavy ion source currents are made available, the intermediate linac concept has no role to play in RHIC.

4) Combining the above results strongly suggests that the introduction of an intermediate Linac to match $h=1$ to $h=3$ heavy ion injection cycles of the Booster is not practical with presently available heavy ion sources. In particular, the results of Table 3 show clearly that in order to achieve the required intensity of $2.2 \times 10^{9}$ ions per bunch in the booster, that the $h=1$ mode has to be made avilable.

For instance, if we focus on an eight turn injection scheme, and a 110 $\mu s$ pulse from the Tandem, arrangement $E$ of figure 1, with the intermediate Linac, would require a source current of $7.33 \mathrm{~mA}$ for ${ }^{197} \mathrm{Au}$. On the contrary the so-called standard injection scheme with no Linac (arrangement A of figure 1) would require $180 \mu \mathrm{A}$ for the same pulse length in an $h=1$ mode but $540 \mu \mathrm{A}$ in the $h=3$ mode. At the present time approximately ${ }^{2} 90 \mu \mathrm{A}$ are available for ${ }^{197} \mathrm{Au}$.

5) The discussions and results of this paper obviously show that the intermediate Linac idea only makes sense if technological leaps are made in heavy ion sources in the future. We note major developments are currently under way at both Argonne and GSI in Damstadt. 


\section{References}

1) "Conceptual Design of the Relativistic Heavy Ion Collider, RHIC", BNL 51932, May 1986.

2) M.J. Rhoades-Brown and A.G. Ruggiero, "Source Current into the AGS, An Analysis of the RHIC Front End Injection System", AD/RHIC Technical Note No. 54.

3) Y.Y. Lee, private communication.

4) J. Wei and S.Y. Lee, "Simulation of Multi-Turn Heavy Ion Injection on the Booster", Booster Technical Note No. 102. 


\section{Figure Captions}

Figure 1. Schematic diagram of the standard injection scheme (Arrangement A), and the injection schemes with an intermediate Linac (Arrangements $B$ and $E$ ), to be considered here.

Figure 2. Graph of booster rf frequency for $h=1$ at injection verses Linac voltage in MV. The threshold values for the species ${ }^{12} \mathrm{C},{ }^{28} \mathrm{~S}$ and ${ }^{63} \mathrm{C}$ are shown by arrows. The dotted line is for arrangement $\mathrm{B}$ and the solid line for arrangement $\mathrm{E}$.

Figure 3. Graph of booster $r f$ frequency for $h=1$ at injection verses Linac voltage in MV. The threshold values for the species ${ }^{127} \mathrm{I}$ and ${ }^{197} \mathrm{Au}$ are shown by arrows. The dotted line is for arrangement $B$ and the solid line for arrangement $\mathrm{E}$. 
FIGURE I

A)

$\otimes$

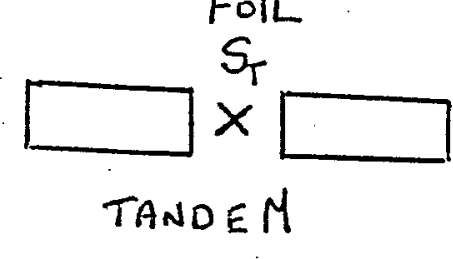

Foil

(x) $S_{T}$

SOURCE

TANDEM

Q)

Foll

$S_{T}$

SOURCE

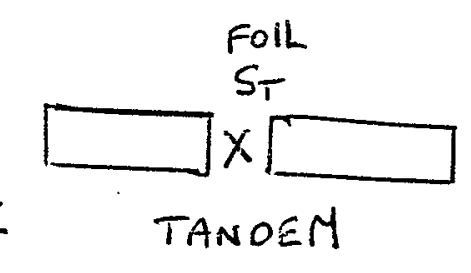

Foll

$S_{F}$

$\times$
Foll

$S_{B}$

$X \Rightarrow A . G . S$.
Foll

$S_{F}$

$X$

LINA

Foll

$S_{F}$

$X$
Foll

$x^{S_{B}} \Rightarrow A . G . S$.

BOOSTER

Foll $X$

$\Rightarrow A \cdot G \cdot S$.

LINAC

BOOSTER 


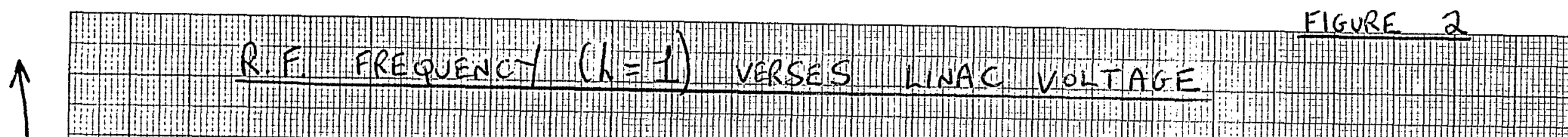

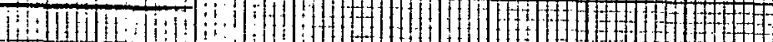
… 2.

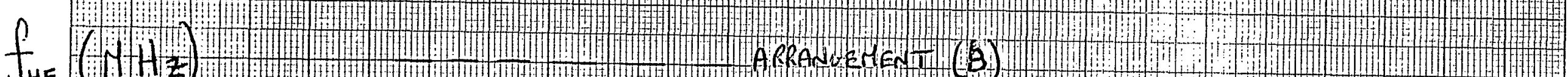
$\mathcal{J}_{\mathrm{HF}}(\mathrm{AHz}$

.8 -

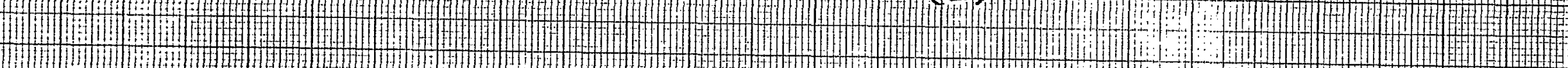
H. +

7 2.

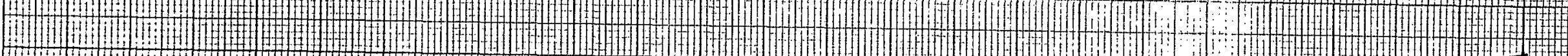

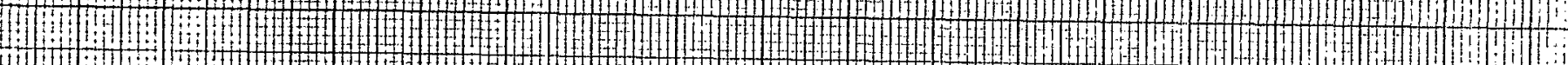

$\cdot 6$
$\checkmark$

. 5 (1)

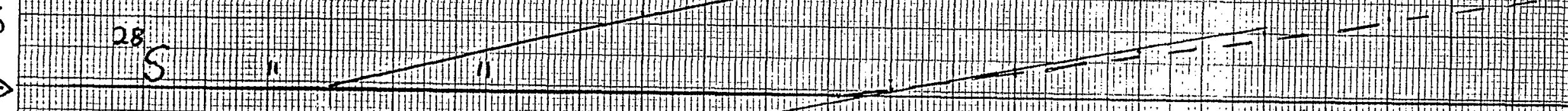

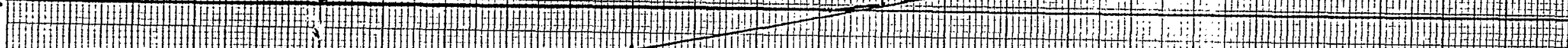

4 63 .

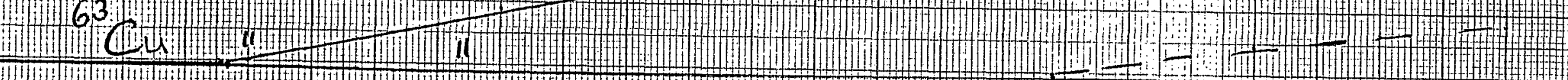
-

3

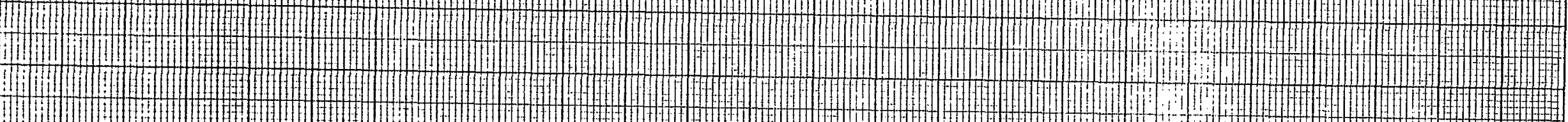

$\cdot 2$

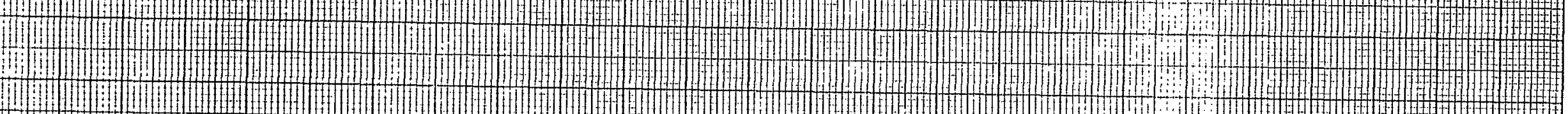

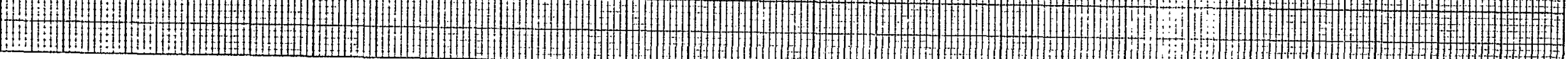

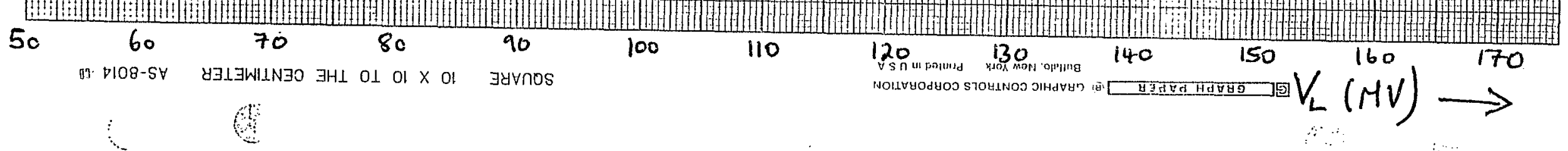


EIGURE 3

人 $\mathcal{J}_{\mathrm{H}} \mathrm{F}(\mathrm{C}-\mathrm{f} 2 \mathrm{z}$

.8 -1. 5.

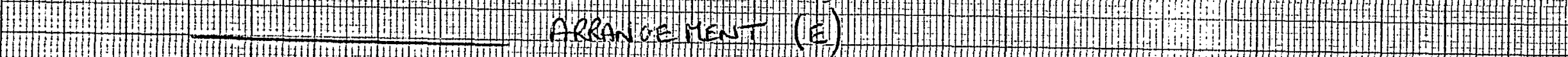
1 (1).6.

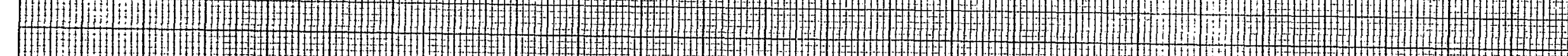
ב. DI: 1.:-1.

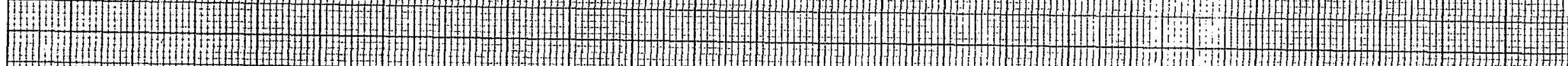

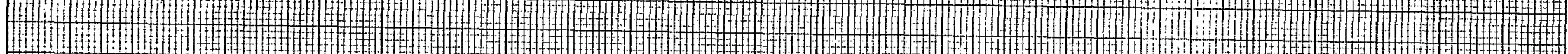

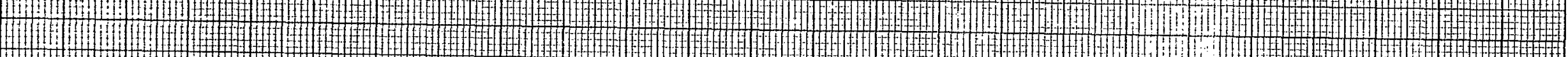

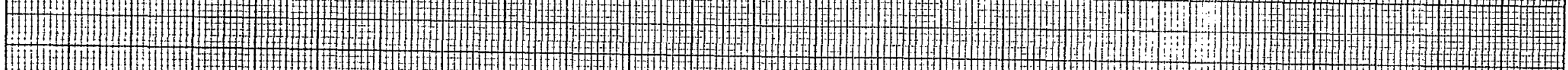

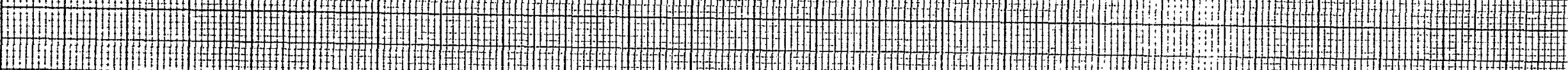
2. D.

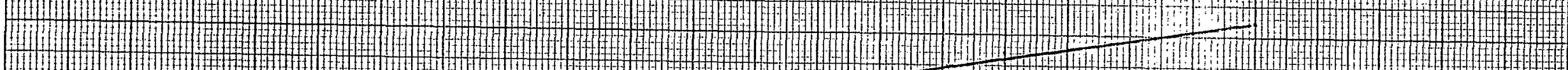

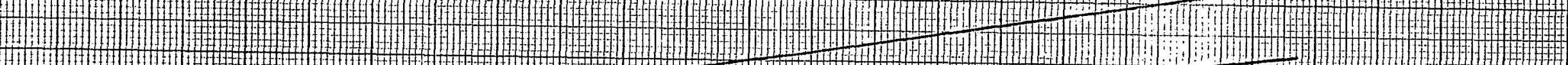

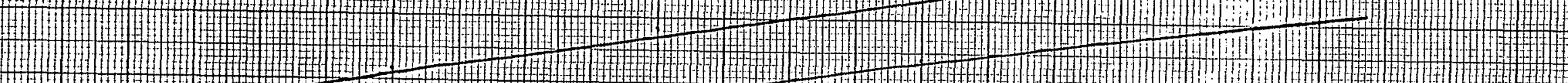

$\cdot 3$

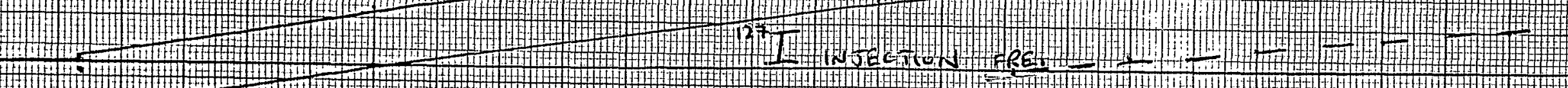

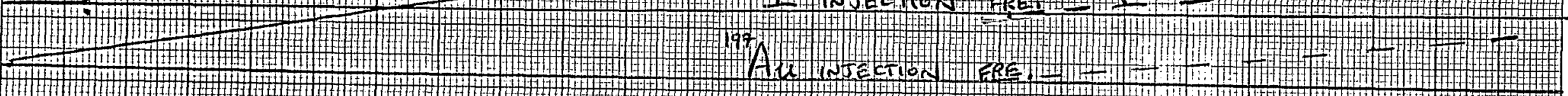

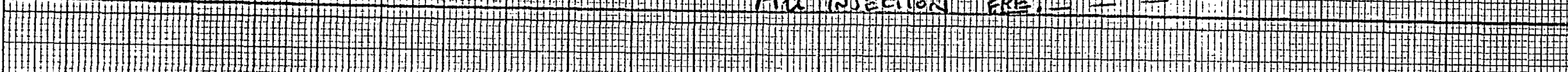

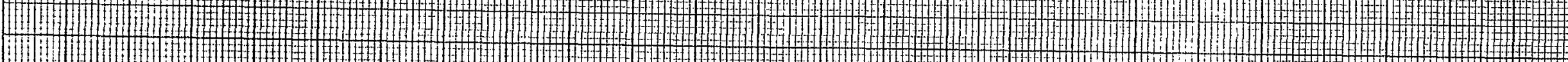

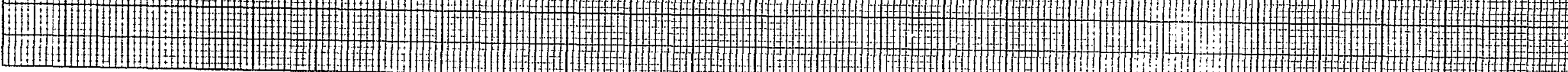

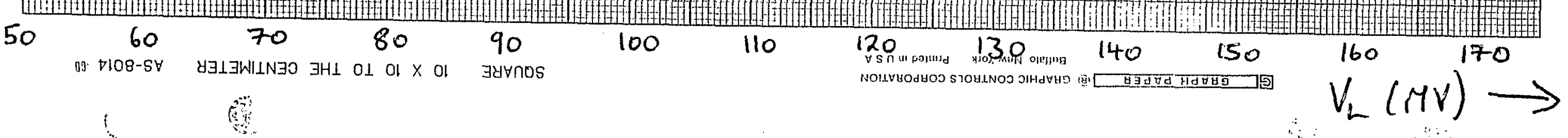

